\title{
Article \\ Polydopamine-Coated Copper-Substituted Mesoporous Silica Nanoparticles for Dual Cancer Therapy
}

\author{
Prabhakar Busa ${ }^{1}(\mathbb{D})$, Ravindranadh Koutavarapu ${ }^{2, *(D)}$ and Yaswanth Kuthati ${ }^{1, *}$ \\ 1 Department of Anesthesiology, Cathay General Hospital, Taipei 280, Taiwan; Prabhakar.busa01@gmail.com \\ 2 Department of Robotics and Intelligent Machine Engineering, College of Mechanical and IT Engineering, \\ Yeungnam University, Gyeongsan 712-749, Korea \\ * Correspondence: ravindra.physicist@gmail.com (R.K.); yaswanthk1987@gmail.com (Y.K.)
}

check for updates

Citation: Busa, P.; Koutavarapu, R.; Kuthati, Y. Polydopamine-Coated Copper-Substituted Mesoporous Silica Nanoparticles for Dual Cancer Therapy. Coatings 2022, 12, 60. https://doi.org/10.3390/ coatings 12010060

Academic Editor: Adriano Sacco

Received: 5 December 2021

Accepted: 31 December 2021

Published: 5 January 2022

Publisher's Note: MDPI stays neutral with regard to jurisdictional claims in published maps and institutional affiliations.

Copyright: (C) 2022 by the authors. Licensee MDPI, Basel, Switzerland. This article is an open access article distributed under the terms and conditions of the Creative Commons Attribution (CC BY) license (https:// creativecommons.org/licenses/by/ $4.0 /)$.

\begin{abstract}
Combinational therapy using chemodynamictherapy (CDT) and photothermal therapy (PTT) is known to enhance the therapeutic outcome for cancer treatment. In this study, a biocompatible nano formulation was developed by coating polydopamine (PDA) over doxorubicin (DOX)-loaded copper-substituted mesoporous silica (CuMSN) nanoparticles. PDA coating not only allowed selective photothermal properties with an extended DOX release but also enhanced the water solubility and biocompatibility of the nanocomposites. The nanocomposites displayed a monodispersed shape and $\mathrm{pH}$-dependent release characteristics, with an outstanding photothermal conversion and excellent tumor cell inhibition. The cellular-uptake experiments of CuMSN@DOX@PDA in A549 cells indicated that nanoparticles (NPs) aided in the enhanced DOX uptake in tumor cells compared to free DOX with synergistic anti-cancer effects. Moreover, the cell-viability studies displayed remarkable tumor inhibition in combinational therapy over monotherapy. Thus, the synthesized CuMSN@DOX@PDA NPs can serve as a promising platform for dual cancer therapy.
\end{abstract}

Keywords: copper-substituted mesoporous silica (CuMSN); chemodynamictherapy (CDT); photothermal therapy (PTT); doxorubicin (DOX); A549 cancer cells and combinational therapy

\section{Introduction}

Cancer remains one of the leading causes of death worldwide [1,2]. Currently, chemotherapy is one of the most commonly used treatments, and often results in drug resistance and adverse effects to the neighboring healthy cells without selectivity $[3,4]$. To address this, combinational treatment therapies have been developed that can limit resistance and adverse events [5-7]. Combination of chemotherapy with phototherapy can greatly enhance the selectivity towards cancer cells. In addition, combination with a photothermal agent can further enhance the anti-cancer effects [8-11].

Doxorubicin (DOX) is one of the most promising anti-cancer drugs used for the treatment of various types of cancers such as lung, breast, throat, skin, and blood [12,13]. DOX can interfere with DNA synthesis, produce reactive oxygen species (ROS), and induce DNA and mitochondrial damage [14,15]. In recent years, with the advent of nanotechnology, various formulations have been developed using DOX for the selective delivery of drugs into cancer cells [16,17]. Various nanocarriers have been reported for the delivery of DOX, such as polymeric NPs, layered double hydroxide NPs, gold NPs, silver NPs, and mesoporous silica (MSN) NPs [18-21]. Among all, MSNs have garnered significant attention due to their peculiar characteristics like ease of synthesis, large surface area and pore volume, ability to control size and shape, biocompatibility, and surface functionality [22-24]. The large surface area and pore volume aids in a high drug loading of therapeutics like small-molecule drugs, proteins, and genes [25-27]. In general, therapeutics are loaded into a mesoporous framework though adsorption [28-30]. The open pore structure facilitates the easier release of drugs when necessary, and to promote prolonged drug release, the surface can be modified with polymers [31-33]. 
In general, cancerous cells have lower extra cellular $\mathrm{pH}(\mathrm{pH}=6.5)$ than healthy cells. To exploit this selective difference, $\mathrm{pH}$-responsive polymers have gained a great deal of attention in the development of nanocarriers for selective drug release in cancerous cells [34-36]. Abnormal pH is a common hallmark in most cancerous cells, a fact that is utilized to design $\mathrm{pH}$-responsive polymers that can alter their physiochemical properties specific to $\mathrm{pH}$. Moreover, nanopolymer size in combination with $\mathrm{pH}$-responsive drug release can strengthen targeting ability $[37,38]$.

In the current work, copper-substituted MSN was prepared by co-condensation. Metal substitution can impart benefits including size reduction, enhanced biocompatibility, reduction of negative charge, improved drug loading, and enhanced stability [39-42]. PDA is used as a surface polymer for the $\mathrm{pH}$-dependent release of anticancer cargo [43,44]. The PDA coating further served as a photothermal agent, enhancing the synergistic effects of phototherapy and chemotherapy $[45,46]$. PDA is coated by the oxidative selfpolymerization of dopamine monomers in the presence of weak alkaline conditions (pH 8.0-8.5) [47,48]. PDA is coated over NPs' surface for various biological applications [49]. Under neutral $\mathrm{pH}$, PDA coating can ensure the drug molecules remain intact in the mesoporous framework [50]. However, upon encountering acidic $\mathrm{pH}$, PDA dissolves and releases the drug molecules into the cytosol of cancer cells [51]. Yanhong et al. reported MSN@ DOX NPs, coated with PDA and poly (ethylene gycol) (PEG), for the management of breast cancer. In this report, PDA acted as a $\mathrm{pH}$-sensitive gatekeeper with photothermal properties [52]. In another report, MSN@DOX NPs were coated with PDA and further conjugated with CSNRDARRC peptide for site-specific DOX delivery with enhanced anticancer effects [53].

In this study, DOX-loaded PDA-coated copper-substituted (CuMSN) were developed, and their anticancer efficacy is evaluated against A549 (lung cancer) cells. The particle size, zeta potential, drug-loading capacity (LC), and in vitro drug-release studies ( $\mathrm{pH}$ - and lightresponsive) were verified. 3-(4,5-dimethyl-2-thiazolyl)-2,5-diphenyl tetrazolium bromide (MTT) assay is used to evaluate the anti-cancer effects of monotherapy and combinational therapy. The cellular uptake of DOX-loaded and fluorescein isothiocyanate (FITC)-labeled NPs was examined by fluorescence microscopy. The intracellular ROS levels were detected by $2^{\prime}, 7^{\prime}$-dichlorodihydroflurescein diacetate (DACFDA) assay.

\section{Materials and Methods}

\subsection{Materials}

DOX, DCFDA, dopamine, tetraethyl orthosilicate (TEOS), cetyltrimethylammonium bromide (CTAB), ammonium nitrate $\left(\mathrm{NH}_{4} \mathrm{NO}_{3}\right)$, copper nitrate, FITC, potassium bromide (FT-IR grade), copper nitrate trihydrate $\left(\mathrm{Cu}\left(\mathrm{NO}_{3}\right)_{2} \cdot 3 \mathrm{H}_{2} \mathrm{O}\right), 4^{\prime}, 6$-diamidino-2-phenylindole dihydrochloride (DAPI), and sodium hydroxide were obtained from Sigma Co. Ltd. (St. Louis, MO, USA).

\subsection{Synthesis of CuMSN}

NPs were prepared by following the previous publications [25]. TEOS is used as silica precursor; $\left(\mathrm{Cu}\left(\mathrm{NO}_{3}\right)_{2} \cdot 3 \mathrm{H}_{2} \mathrm{O}\right)$ is used as a copper source, and CTAB is employed as a surfactant in the basic solvent to perform the co-condensation reaction to synthesize the uniformly sized CuMSN. In detail, firstly, $0.58 \mathrm{~g}$ of CTAB was dissolved in $300 \mathrm{~mL}$ of $\mathrm{NH}_{4} \mathrm{OH}(0.51 \mathrm{M})$ and stirred with constant speed at $40{ }^{\circ} \mathrm{C}$. A total of $5 \mathrm{~mL}$ of dilute TEOS ( $0.2 \mathrm{M}$ TEOS in $5 \mathrm{~mL}$ of ethanol) is added and was continuously stirred for $3 \mathrm{~h}$. After $3 \mathrm{~h},\left(\mathrm{Cu}\left(\mathrm{NO}_{3}\right)_{2} \cdot 3 \mathrm{H}_{2} \mathrm{O}\right)$ and $5 \mathrm{~mL}$ of concentrated TEOS $(1.0 \mathrm{M}$ in $5 \mathrm{~mL}$ of ethanol) was added and stirred for another $2 \mathrm{~h}$. Then, the stirring is stopped, and the reaction mixture is aged for $20 \mathrm{~h}$ at $40^{\circ} \mathrm{C}$. The contents are centrifuged and collected, and chemical composition was explained in the supplementary (Table S1). Surfactant CTAB is extracted by suspending $100 \mathrm{mg}$ of CuMSN in a mixture of $0.3 \mathrm{~g}$ of $\mathrm{NH}_{4} \mathrm{NO}_{3}$ in isopropanol $(40 \mathrm{~mL})$ for $16 \mathrm{~h}$. Finally, CuMSN was collected by centrifugation and washed two times with 
ethanol and isopropanol. The solid was dried under vacuum at room temperature, and the product was named CuMSN-extd.

\subsection{DOX Loading into CuMSN}

Initially, $6 \mathrm{mg}$ of DOX was dissolved in $6 \mathrm{~mL}$ of dry methanol, and the $\mathrm{pH}$ was adjusted to 5.8 to 6.0. The DOX solution was transferred into a glass container with $100 \mathrm{mg}$ dried CuMSN NPs, and the contents were stirred at room temperature overnight in a dark environment [54]. The DOX-loaded solid contents were collected by centrifugation and washed twice with ethanol and methanol to remove the unbound DOX molecules. The loading percentage was calculated by using the formula mentioned below.

$$
\begin{gathered}
\text { Drug Entrapment Efficacy \% }(\text { DEE \% })=\frac{\text { weight of drug in nanoparticle }}{\text { weight of drug used in formulation }} \times 100 \\
\text { Drug Loading Capacity \% (DLC \% })=\frac{\text { weight of drug in nanoparticle }}{\text { weight of nanoparticle }} \times 100
\end{gathered}
$$

Approximately $8 \%(w / w)$ DOX was loaded into CuMSN. The DOX load was measured at $480 \mathrm{~nm}$. The product was named CuMSN@DOX.

\subsection{PDA Coating onto CuMSN@DOX}

The PDA was coated onto CuMSN@DOX NPs by following the previous publications $[48,55]$. Initially, $50 \mathrm{mg}$ of CuMSN@DOX NPs were added into $1 \mathrm{mg} / \mathrm{mL}$ solution of dopamine hydrochloride in Tris buffer $(10 \mathrm{mM}, \mathrm{pH} 8.5)$ and continuously stirred under dark conditions at room temperature for $10 \mathrm{~h}$. PDA-coated black-colored solid was collected by centrifugation and washed thrice with distilled water to remove un-polymerized dopamine molecules from the surface. Then, finally, the solids were dried by freeze dryer and stored at $4{ }^{\circ} \mathrm{C}$. The product was denoted CuMSN@DOX@PDA.

\subsection{In Vitro DOX Releasing Study}

The DOX release profile from the NPs (CuMSN@DOX and CuMSN@DOX@PDA) was verified in various buffers by following previous protocols [32,56]. A total of $5 \mathrm{mg}$ of NPs were suspended in phosphate buffer saline solution (PBS) (pH 5.0 and 7.4) and placed on a shaker $(150 \mathrm{rpm})$ at $37{ }^{\circ} \mathrm{C}$ on a rotary shake machine. The supernatant was collected from the respective buffers at regular time intervals, and the DOX concentration was calculated by Uv-vis spectrometry (Uv-1700 Pharma Spec, Shimadzu, MA, USA) at $480 \mathrm{~nm}$. The collected sample solution was replaced with same amount of fresh PBS. The cumulative DOX-release percentage was calculated periodically; all experiments were performed in triplicate.

\subsection{In Vitro PTT Studies}

PPT experiments were performed by following the previous reports. A total of $1 \mathrm{~mL}$ of quartz cuvette with samples (CuMSN@DOX@PDA) was irradiated with a near-infrared (NIR) light source $\left(808 \mathrm{~nm}, 1 \mathrm{~W} / \mathrm{cm}^{2}\right)$ [57]. The temperature changes were noted by thermal camera with time (FLIR ONE PRO, Wilsonville, OR, USA).

\subsection{Cell Culture and Cytotoxicity Assay}

A549 and HT-29 cells were obtained from the American Type culture collection (Rockville, MD, USA), cultured in Dulbecco's Modified Eagle's Medium (DMEM) and Roswell Park Memorial-1640 (RPMI-1640) respectively, with 10\% fetal bovine serum (FBS) and $1 \%$ penicillin or streptomycin (antibiotic), passage number 6 . The cells were grown in an incubator and maintained at $37{ }^{\circ} \mathrm{C}$ with $5 \% \mathrm{CO}_{2}$ supply. MTT assay was used to determine the CDT and PTT groups' cell viability. For CDT and PTT therapy, cells were seeded in the 96-well plate at $1 \times 10^{5}$ cells per well and incubated for $24 \mathrm{~h}$. After $24 \mathrm{~h}$, for CDT therapy, the wells were treated with respective NPs, and PTT experiments are performed by utilizing a light source $(810 \mathrm{~nm}, 1.0 \mathrm{~W} / \mathrm{cm})$ for $5 \mathrm{~min}$ and incubating for $24 \mathrm{~h}$. Finally, all wells are washed carefully with PBS solution. A MTT reagent was added and incubated 
for 20 min. Finally, Formazan crystals were dissolved in the dimethyl sulfoxide (DMSO), and the absorbance was recorded by using a micro plate reader [48]. All experiments were performed in triplicate for the individual experiments.

\subsection{Cell Uptake Studies}

The drug-delivery capacity of CuMSN and its modified counterparts was evaluated in vitro through cell-uptake studies in A549 cells through fluorescence microscopy (Olympus BX51, NY, USA). The DOX self-fluorescence gave the ability to check the internalization capacity. A549 cells were seeded onto 6-well plates at a density of $1 \times 10^{5}$ cells per well and incubated for $24 \mathrm{~h}$. CuMSN and their modified samples were suspended in the FBS-free culture medium with $50 \mu \mathrm{g} / \mathrm{mL}$ and added to the respective wells. After $4 \mathrm{~h}$ of incubation, the cells were fixed with $4 \%$ paraformaldehyde and incubated for another $10 \mathrm{~min}$. Finally, the nuclei were stained with DAPI, and all wells were carefully washed with PBS solution twice. Ultimately, the images were captured by fluorescence microscopy $[58,59]$.

\subsection{ROS Detection Assay}

The cellular level ROS generation was assessed by DCFDA assay by following previous protocols [60,61]. A549 cells were seeded in the 96-well plates at a density of $1 \times 10^{5}$ cells per well and incubated for $24 \mathrm{~h}$ for the bottom attachment of cells to carry out experiments smoothly. Then, the respective wells are treated with CuMSN and their successive modified nanoparticles with $100 \mu \mathrm{g} / \mathrm{mL}$; for the PPT group, the experimental procedure was performed with the same experimental condition by using a light source. Herein, after $24 \mathrm{~h}$ of nanoparticle treatment, all wells were exposed to a DCFDA solution $(5 \mu \mathrm{g} / \mathrm{mL})$ and incubated for $30 \mathrm{~min}$. The fluorescence intensity was detected by a micro plate reader with Coring (Glendale, AZ, USA) plates having a transparent bottom and black side walls. Hydrogen peroxide was used as negative control, and all experiments were performed in triplets with individual experiments.

\subsection{Statistical Analysis}

All data are represented as mean \pm standard deviation (S.D). In experiments, $p \leq 0.001\left(^{* * *}\right)$, $p \leq 0.01\left(^{* *}\right)$, and $p \leq 0.5\left(^{*}\right)$ were statistically significant. The data were analyzed by a Student t-test to compare the mean values. Graph pad prism- 5 software was used to calculate all statistical significance.

\section{Results and Discussion}

The material design of our multifunctional nanomaterial is depicted in Figure 1. The aim of the proposed design is to deliver DOX into A549 cells and eradicate them by synergistic CDT/PTT. Initially, we synthesized CuMSN by a co-condensation method in the basic medium composed of TEOS and copper silts using CTAB as a template. The presence of copper $(\mathrm{Cu}(\mathrm{II}))$ within the MSN framework enables the formation of a coordination link with DOX, which triggers $\mathrm{pH}$-sensitive drug release at acidic $\mathrm{pH}$ conditions (endosomal level). The metal substitution can also enhance the DOX loading. Additionally, the PDA coating aims to improve the biocompatibility and cellular internalization of NPs, along with photothermal properties. The PDA layer is coated onto the nanoparticle surface in the presence of alkaline conditions (Tris buffer ( $\mathrm{pH}$ 8.0-8.5)). Dopamine undergoes oxidative polymerization in the oxygenated environment (oxidant). Firstly, the synthesized NPs were physically characterized by different techniques such as transmission electron microscopy (TEM, Hitachi HT7700, Tokyo, Japan) for morphological analysis, Fouriertransform infrared spectroscopy (FT-IR, Bruker's Tensors 27 series, TX, USA) for functional group detection, and thermogravimetric analysis (TGA, TG Q500, New castle, DE, USA) studies for the weight-loss determination of respective compounds. Uv-vis (Uv-1700 Pharma Spec, Shimadzu, MA, USA) is performed to determine the loading percentage and drug-release profile of DOX, and dynamic light scattering (DLS, Zetasizer Nano ZS-90, Malvern, UK) is used to evaluate the particle-size distribution and zeta potential. 
Furthermore, the synergistic CDT/PTT effects of nanocarriers are studied in A549 cancer cells by MTT assay, and ROS levels were determined using DCFDA assay [62,63].

(A)

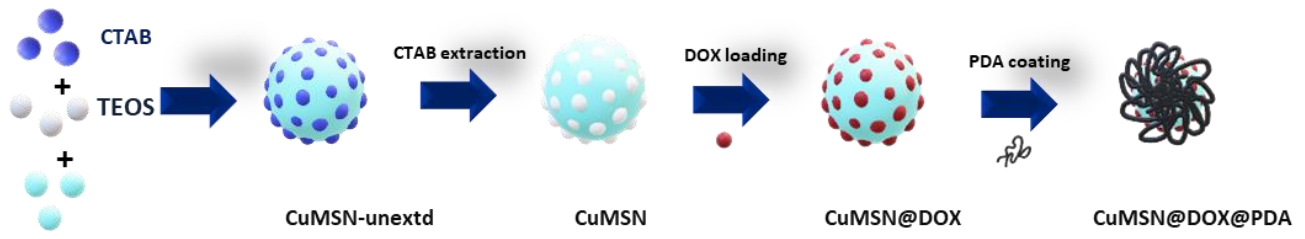

(B)

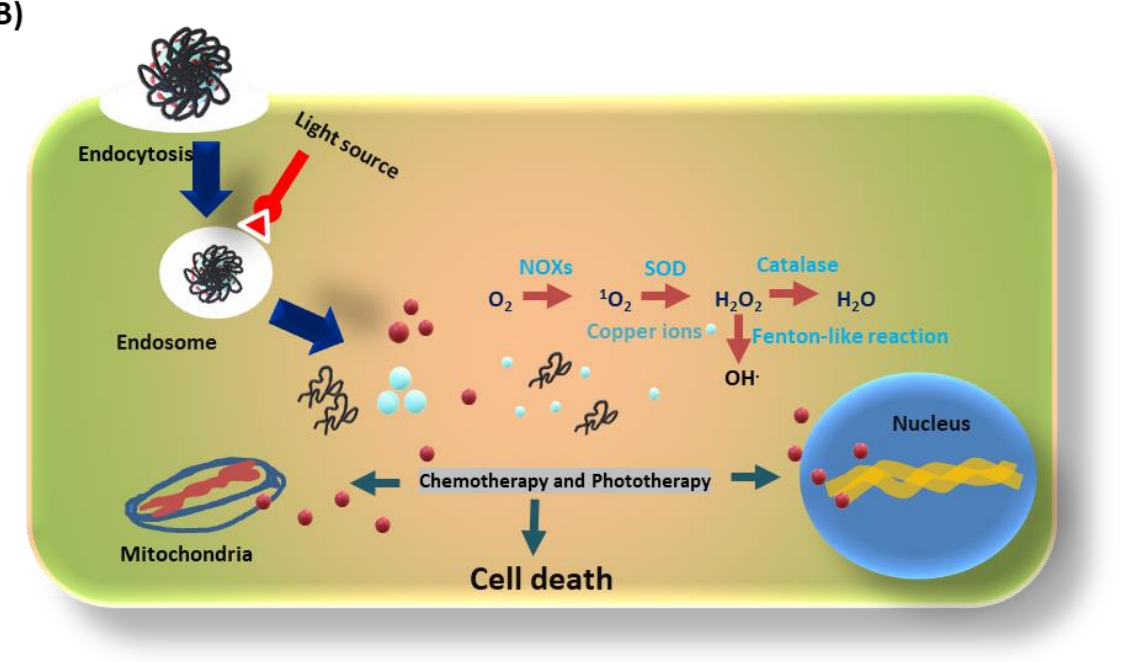

Figure 1. (A) Schematic explanation of CuMSN, DOX loading, and PDA coating onto the surface and (B) a graphical description of chemotherapy and photothermal therapy killing the A549 cancer cells.

\subsection{Physical Characterization}

TEM images (Figure 2A) show that CuMSN@DOX-loaded NPs retained their spherical shape after drug loading, without disturbing the mesoporous structure. After PDA coating, a rough surface was detected with a dense core, indicating the successful binding of DOX within the mesopores of CuMSN. PDA coating did not affect the loading of DOX and served as a gatekeeper. The size distribution of NPs in the TEM is consistent with the DLS size-distribution studies shown in Figure 2B. Furthermore, we studied the changes in hydrodynamic size and zeta potential values of CuMSN before and after drug loading and PDA coating. The average hydrodynamic diameter of unextracted CuMSN (CuMSNUnextd), CTAB extracted (CuMSN-extd), and DOX-loaded (CuMSN@DOX) NPs are around 100-160 nm. Furthermore, PDA coating (CuMSN@DOX@PDA) resulted in a gradual increase of the NPs size to $210 \mathrm{~nm}$, suggesting the successful coating of PDA on the surface of NPs. Liu et al. studied the distribution of the radiolabeled NPs of various sizes ranging from $30-400 \mathrm{~nm}$ in tumor tissue. Their studies revealed that NPs within 100-200 nm have four times higher retention than the NPs larger than $300 \mathrm{~nm}$ and less than $50 \mathrm{~nm}$ [64]. 
(A)
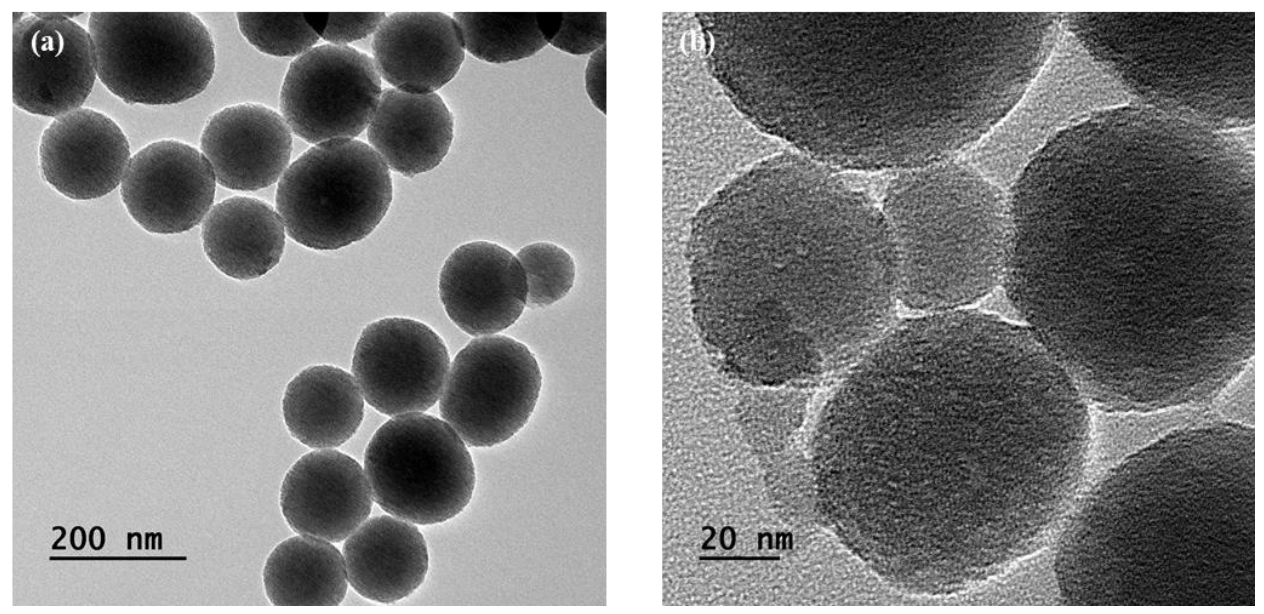

(B)

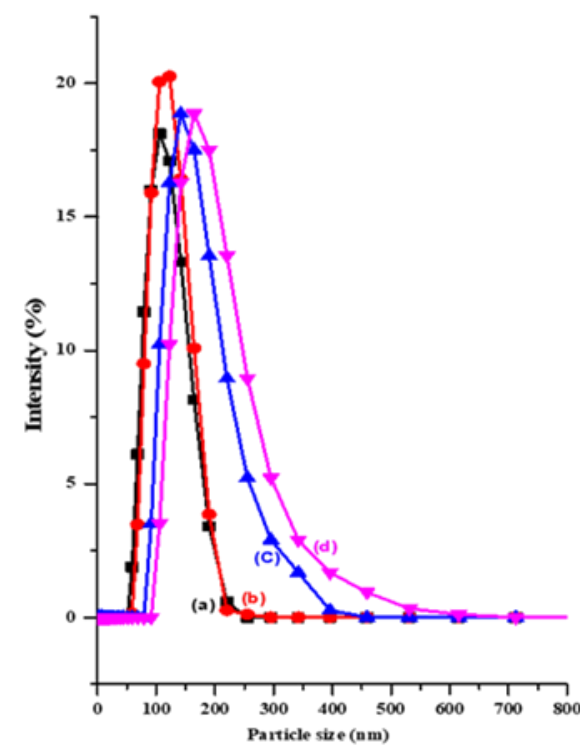

(C)

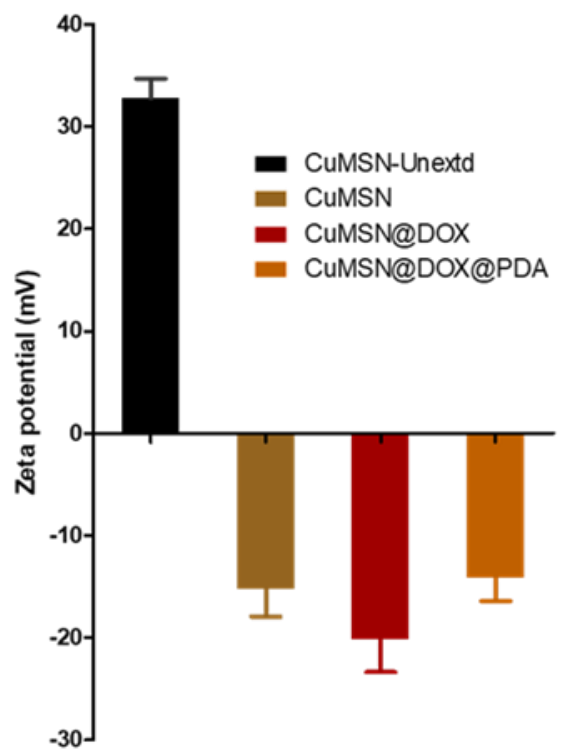

Figure 2. (A) TEM images of (a) DOX-loaded and (b) PDA-coated CuMSN and (B) hydrodynamic sizes of (a)CuMSN-Unextd, (b) CuMSN, (c)CuMSN@DOX, and (d)CuMSN@DOX@PDA. (C) Zeta potential charges of CuMSN and their modifications, respectively. Data represent mean \pm s.d., $n=3$.

Furthermore, the pristine MSN have a negative surface charge after CTAB extraction, but the extraction of a template resulted in a slight decrease of negative zeta potential $(-17 \pm 0.2 \mathrm{mV})$ due to the presence of copper ions in the MSN framework. After DOX loading, the zeta potential shifted to the negative side. However, PDA coating resulted in a positive zeta potential, implying PDA coating on to the surface of NPs.

Furthermore, FT-IR spectral studies gave evidence of various functional groups in the silica framework (Figure 3A). The broad band at $3450 \mathrm{~cm}^{-1}$ can be attributed to $\mathrm{O}-\mathrm{H}$ stretching vibration and surface $\mathrm{Si}-\mathrm{OH}$ functional groups from the water molecules (Figure 2B (a-d)). The nanoparticle surface silanol functional groups Si-O-Si are verified at 790 and $1085 \mathrm{~cm}^{-1}$, and $\mathrm{Si}-\mathrm{O}-\mathrm{H}$ functional groups are seen at $970 \mathrm{~cm}^{-1}$, which represent the stable formation of a silica framework in all of the samples. The $\mathrm{C}-\mathrm{H}$ stretching peaks appeared at around 2800 to $2930 \mathrm{~cm}^{-1}$ in the unextracted CuMSN (Figure 3A (a)). After CTAB extraction by chemical etching, these peaks vanished, denoting the successful removal of surfactants. After CTAB extraction, the characteristic peaks of the silica framework remained the same, demonstrating the stability of the nanocarrier. DOX-loaded CuMSN (Figure 3A (c)) show peaks at around $1690 \mathrm{~cm}^{-1}$, corresponding to the aliphatic 
carbonyl group. Other peaks at $1549 \mathrm{~cm}^{-1}$ can be attributed to amine groups. The broad peak at $2940 \mathrm{~cm}^{-1}$ can be attributed to $\mathrm{C}-\mathrm{H}$ vibrations of DOX and is similar to previous publications [65-68]. The N-H vibrational peaks appearing at 1520 to $1550 \mathrm{~cm}^{-1}$ from DOX gives evidence for coordination interactions and the successful loading of DOX into the mesopores of NPs. Furthermore, DOX loading was confirmed by TGA and Uv-vis spectral analysis. The broad peaks at 3130 to $3600 \mathrm{~cm}^{-1}$ are attributed to $\mathrm{N}-\mathrm{H}$ and $\mathrm{O}-\mathrm{H}$ stretching vibration of PDA (Figure 3A (d)), and the peak at $1650 \mathrm{~cm}^{-1}$ is assigned for the C-C resonance stretching vibrations in the aromatic rings. These results suggest the successful coating of PDA onto the surface of NPs without disturbing the DOX and NPs' framework.

(A)

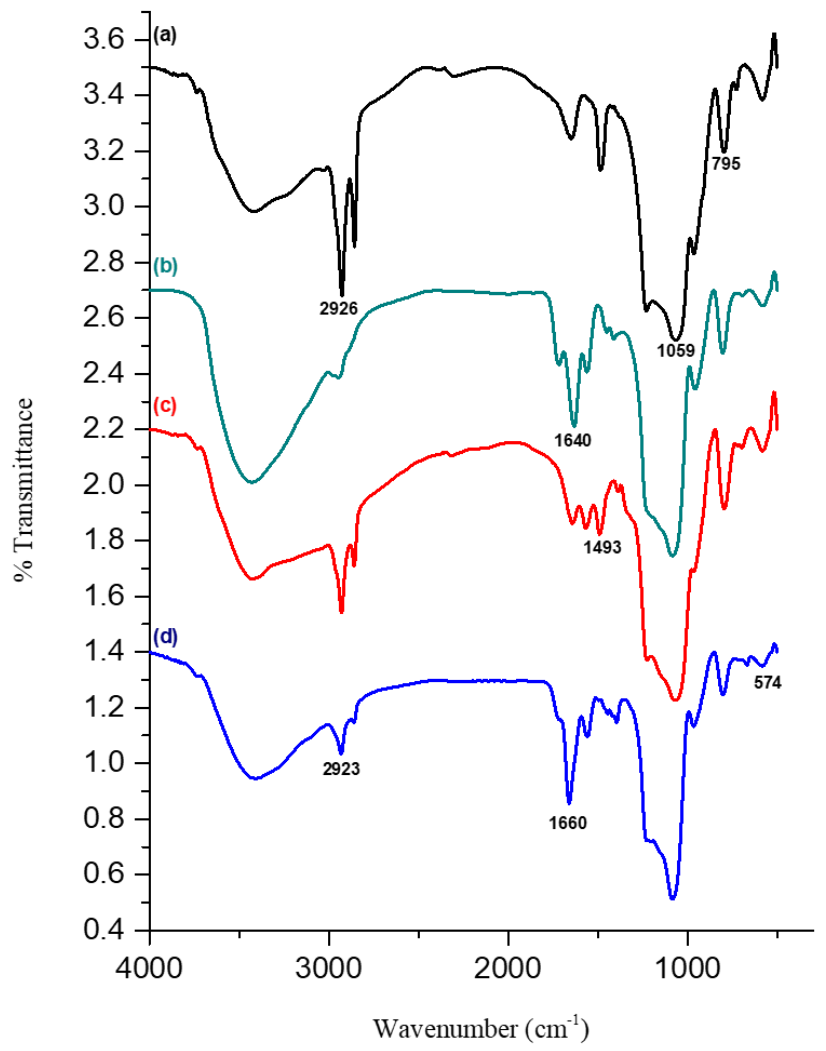

(B)

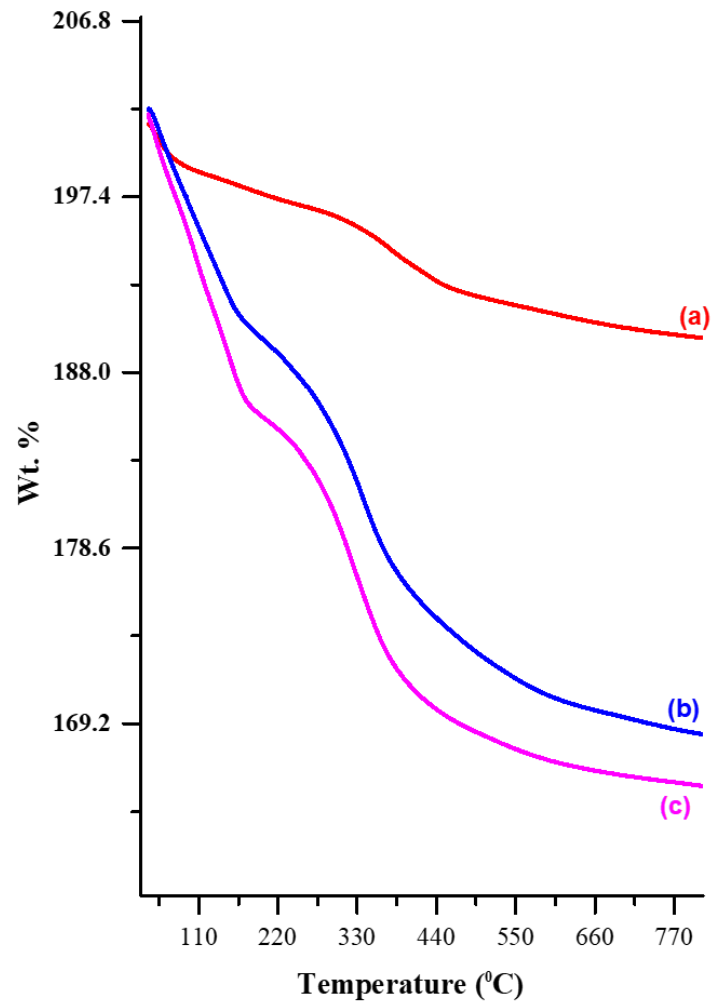

Figure 3. (A) FT-IR analysis of (a) CuMSN-Unextd, (b) CuMSN-extd, (c) CuMSN@DOX, and (d) CuMSN@DOX@PDA and (B) TGA curves of (a) CuMSN-Unextd, (b) CuMSN@DOX, and (c)CuMSN@DOX@PDA.

Next, the drug loading and thermal properties of CuMSN and their succeeding modifications were evaluated by TGA studies. Figure $3 \mathrm{~B}$ shows the TGA curves of various nanocomposites. The early stage of weight loss before $100{ }^{\circ} \mathrm{C}$ in all samples corresponded to a loss of residual water. In unextracted CuMSN (Figure 3B (a)), weight loss at around $240{ }^{\circ} \mathrm{C}$ results from the degradation of CTAB. DOX-loaded NPs show a significant weight loss at $310^{\circ} \mathrm{C}$, which is equivalent to the amount of DOX loaded ( 8\%) into the mesopores. This weight-loss percentage supports the estimated drug load reported through UV-vis measurements. The PDA-loaded samples began a gradual loss of weight at $250{ }^{\circ} \mathrm{C}$ and continued until $550^{\circ} \mathrm{C}$. This significant loss of DOX and PDA events overlapped at $420^{\circ} \mathrm{C}$. These findings demonstrated that PDA was successfully coated onto the surface of the nanoparticles and enhanced their thermal stability [69]. 


\subsection{In Vitro DOX Release and PDA Photothermal Studies}

In vitro DOX-release behavior is studied in various buffer solutions (PBS, pH 5.0 and 7.4) using a Uv-vis spectrometer. The $\mathrm{pH}$-sensitive bond between copper ions and amine groups were disrupted in acidic $\mathrm{pH}(\mathrm{pH}$ 5.0) and significantly enhanced the DOX release compared to basic conditions ( $\mathrm{pH}$ 7.4); similar $\mathrm{pH}$-sensitive release profiles have been reported earlier (Figure 4A) [70]. Furthermore, a similar pattern of release is observed in the PDA-coated samples, wherein PDA acts as a gatekeeper and extends the DOX release from the mesopores of the nanoparticles. The PDA coating can help to extend the DOX release in the tumor environment (Figure 4B) [71].

(A)

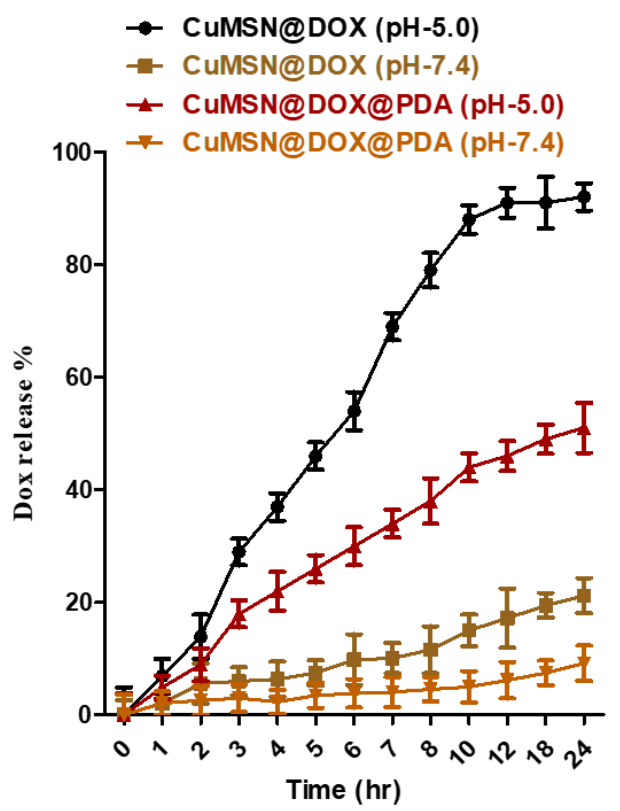

(B)

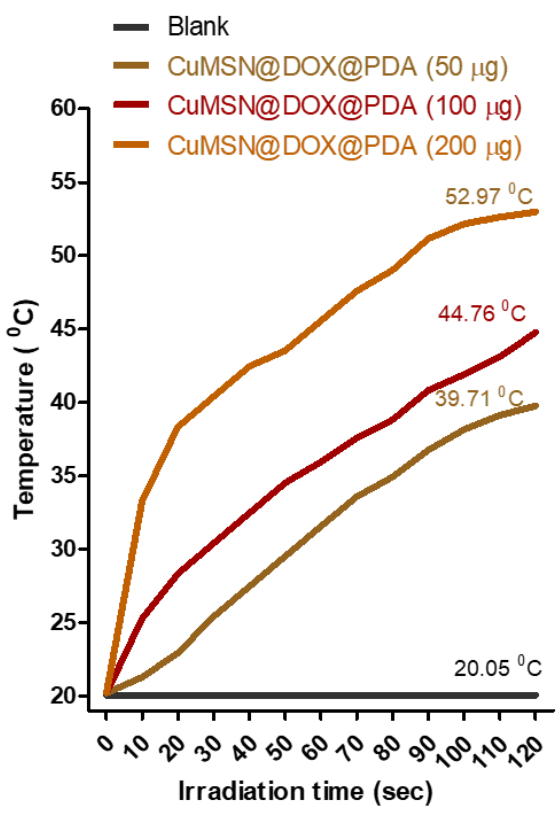

Figure 4. (A) DOX releasing from CuMSN@DOX and CuMSN@DOX@PDA over time at various PBS solutions of $\mathrm{pH} 5.0$ and 7.4 (at $37^{\circ} \mathrm{C}$ ). (B) Temperature increasing profiles of CuMSN@DOX@PDA under $808 \mathrm{~nm}$ laser irradiation over time (50, 100, and $200 \mu \mathrm{g} / \mathrm{mL})$.

Photothermal properties of PDA were investigated by NIR light source $(810 \mathrm{~nm})$ directed towards the cancer cells. The PDA-coated nanoparticles (50, 100 and $200 \mu \mathrm{g} / \mathrm{mL})$ were dispersed in PBS solution, and the samples were irradiated with an NIR light source with various time intervals up to $120 \mathrm{~s}$. The significant temperature increment was observed in a time- and concentration-dependent manner that implies the efficacy of PDA as a photothermal agent to generate the heat to destroy the cancer cells [72,73].

\subsection{In Vitro Cellular-Uptake Studies}

We have evaluated cellular internalization, DOX $\mathrm{pH}$-dependent release, DOX participating in ROS generation by CDT, and CDT/PPT combinational therapy. To deliver DOX into the tumor cells, initially the PDA-coated NPs attached to the cell membranes, followed by internalization, and the DOX was released at the cytosol level due to the $\mathrm{pH}$-sensitive effect. The released DOX molecules participated in the reductive metabolic pathway, in which molecular oxygen was converted to superoxide in the presence of NADPH oxidase (NOX) enzymes. Then, the superoxide was converted to hydrogen peroxide $\left(\mathrm{H}_{2} \mathrm{O}_{2}\right)$ in the presence of copper ions (Fenton-like reaction), yielding hydroxy free radicals. These free radicals were simultaneously involved in several significant events, such as the stimulation of cytochrome $C$, etc. The copper ions were involved in the redox chemistry to generate ROS along with DOX to enhance the CDT action [74,75]. 
The cellular-uptake studies were conducted in A549 cells by using CuMSN and their modified counterparts. These results demonstrated the time-dependent cellular internalization of NPs after $4 \mathrm{~h}$ of incubation. The FITC-labelled CuMSN (Figure 5A) show green fluorescence at the cytosol level, demonstrating the successful internalization of CuMSN into cells. The self-fluorescent property of DOX makes it possible to verify the cell uptake. As shown in Figure 5B, PDA-coated CuMSN@DOX-sample-treated cells showed significant red fluorescence, implying DOX release through the successful internalization of NPs through endocytosis, which is in agreement with previous reports [76].

(A)

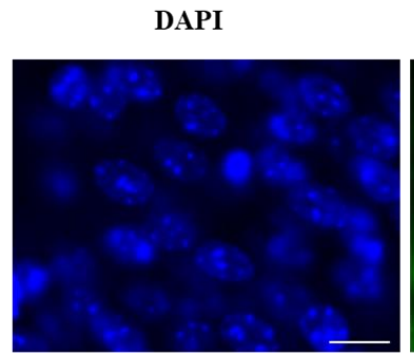

DAPI

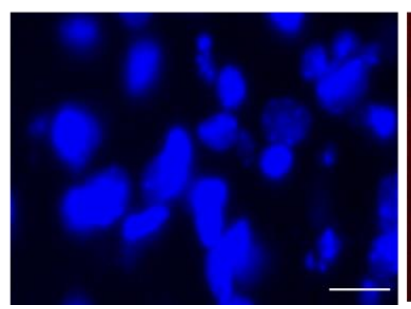

FITC

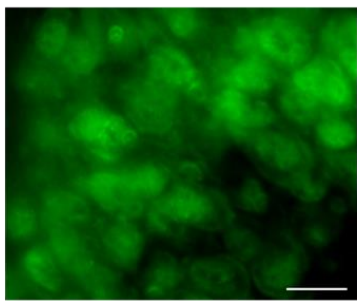

DOX

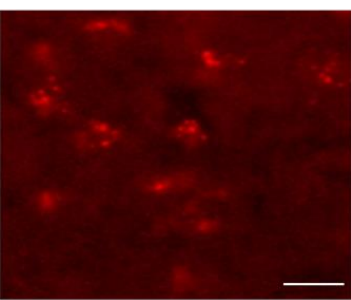

MERGE

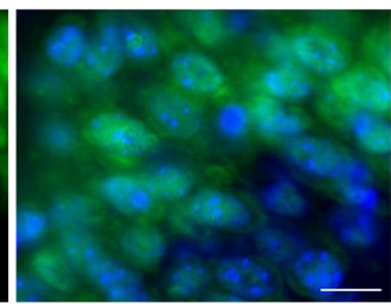

MERGE

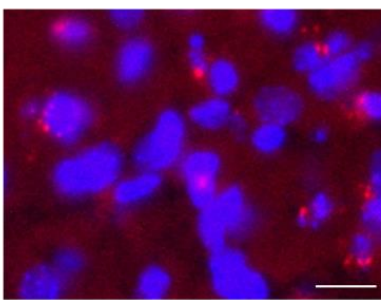

Figure 5. (A) Fluorescence microscopic images of CuMSN $(100 \mu \mathrm{g} / \mathrm{mL})$ cellular uptake with the treatment of FITC-labeled CuMSN $(100 \mu \mathrm{g} / \mathrm{mL})$, and (B) intracellular DOX uptake in A549 cells treated with CuMSN@DOX@PDA (20× magnification) (scale bar $100 \mu \mathrm{m})$.

\subsection{In Vitro Cell-Viability Studies}

The anticancer efficacy of CuMSN and other nanocomposites were verified by MTT assay in A549 cells. The proposed formulation successfully eradicated the cancer cells by ROS production through combinatorial therapy. As Figure 6A shows the PDA-coated CuMSN@DOX samples with an IC 50 value of $1.6 \mu \mathrm{g}$ in the presence of light and $2.90 \mu \mathrm{g}$ in the absence of light. Furthermore, DOX-loaded NPs show better anticancer efficacy at a very low concentration $(2.95 \mu \mathrm{g})$ than that of pure DOX (IC-50-7.5 $\mu \mathrm{g})$. Interestingly, the copper-substituted MSN, together with DOX, enhanced the generation of ROS, and PDA serves as a photothermal agent to achieve CDT/PTT synergetic therapy at a low dose [77-79]. 
(A)
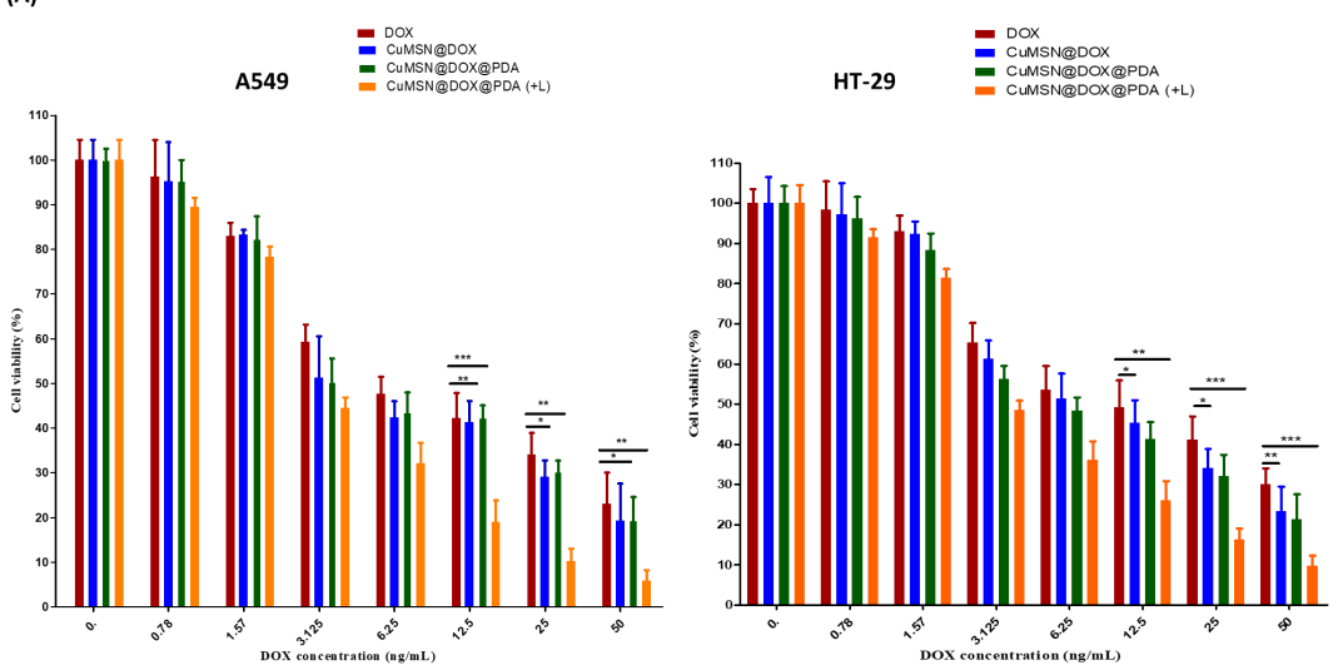

(B)

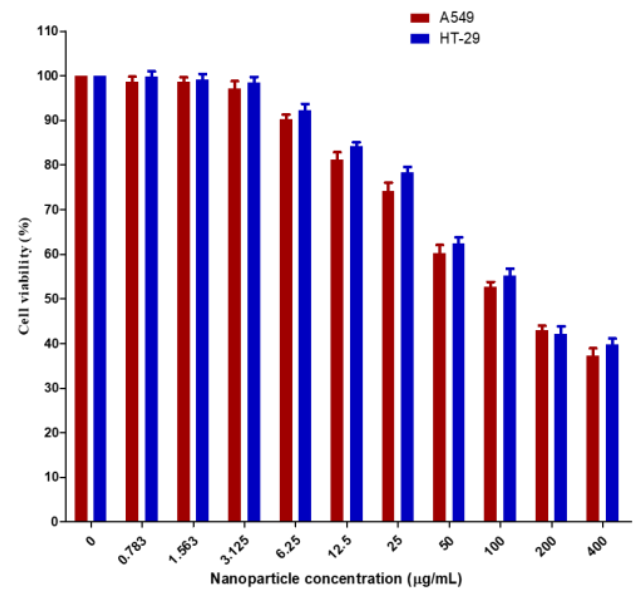

Figure 6. (A) In vitro cell-viability studies on the dose-dependent cell viability of A549 and HT-29 cells incubated with CuMSN, DOX, CuMSN@DOX, CuMSN@DOX@PDA, and CuAl-LDH@DOX@PDA (+L) for $24 \mathrm{~h}$, and CuAl-LDH@DOX@PDA (+L)-treated groups were irradiated with a light source for $5 \mathrm{~min}$ after $24 \mathrm{~h}$ treatment (DOX-equivalent dose). (B) Toxicity profile investigations of the A549 and HT-29 cell with CuMSN. ${ }^{* * *},{ }^{* *}$, and * denotes the significant difference between DOX vs CuMSN@DOX and DOX vs CuMSN@DOX@PDA (+L).

\subsection{ROS Detection}

The synergistic anticancer efficacy of designed NPs against A549 cells can be attributed to the production of ROS at the cellular level. Recently, some groups have reported that DOX, in combination with PDA, can significantly enhance anticancer efficacy by increasing the ROS and thermal energy production, thereby killing cancer cells synergistically. The intracellular ROS levels were detected by DCFDA assay, as shown in Figure 7. The ROS levels of PDA-coated CuMSN@DOX samples was evaluated in the presence and absence of light and compared to the remaining sample groups except the $\mathrm{H}_{2} \mathrm{O}_{2}$ (negative control) group. Our results demonstrated that light significantly increased the level of ROS production through synergistic CDT/PTT therapy, thereby successfully killing the cancer cells $[80,81]$. 


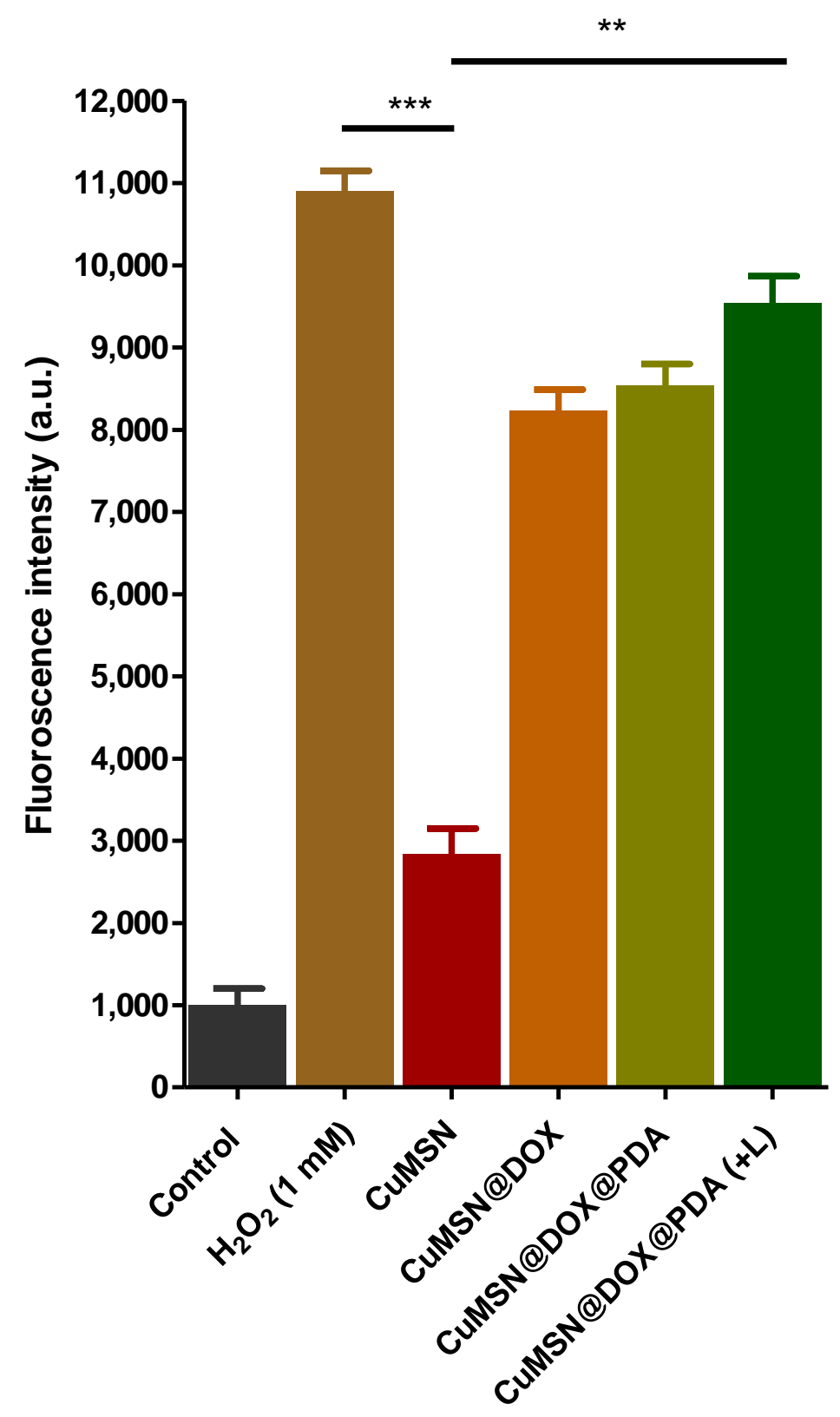

Figure 7. Intracellular ROS production in A549 cells treated with nanoparticles with and without light irradiation by DCFDA assay. The fluorescence signal was detected by a microplate reader $(\lambda \mathrm{ex}=488 \mathrm{~nm}, \lambda \mathrm{em}=535 \mathrm{~nm}) .{ }^{* * *}$, and $^{* *}$ denotes the significant difference between $\mathrm{H} 2 \mathrm{O} 2 \mathrm{vs}$ CuMSN and CuMSN vs CuMSN@DOX@PDA (+L).

\section{Conclusions}

In summary, we designed a biocompatible copper-substituted mesoporous silica nanoparticle for the eradication of cancer cells. The anti-tumor drug DOX was loaded into mesopores by establishing a $\mathrm{pH}$-sensitive bond to overcome premature release. Furthermore, PDA coating served as a PTT agent and gatekeeper along with the extension of DOX release. The physical and in vitro studies revealed that the synthesized CuMSN and modifications are advisable for CDT/PTT therapy. DOX participated in the ROS with copper ions, and PDA generates thermal energy (PTT). This promising approach can synergistically eradicate cancer cells effectively. 
Supplementary Materials: The following supporting information can be downloaded at: https:/ / www.mdpi.com/article/10.3390/coatings12010060/s1, Table S1: Tabular representation of CuMSN NP chemical composition in detail.

Author Contributions: Conceptualization and methodology, software, formal analysis, writingoriginal draft preparation, validation, supervision, editing, resources, and funding, P.B.; validation, formal analysis, investigation, and funding acquisition R.K.; conceptualization, and methodology, software, formal analysis, writing — original draft preparation, validation, resources, and funding, Y.K. All authors have read and agreed to the published version of the manuscript.

Funding: This research was supported by the National Research Foundation of Korea (NRF) funded by the Korea Government (2020R1A2C1012439), Republic of Korea.

Institutional Review Board Statement: We have not conducted any experiments on animals or humans. Informed Consent Statement: Not applicable.

Data Availability Statement: No supporting data is presented in this study.

Conflicts of Interest: The authors declare that they have no known competing financial interests or personal relationships that could have appeared to influence the work reported in this paper.

\section{References}

1. Sung, H.; Ferlay, J.; Siegel, R.L.; Laversanne, M.; Soerjomataram, I.; Jemal, A.; Bray, F. Global Cancer Statistics 2020: GLOBOCAN Estimates of Incidence and Mortality Worldwide for 36 Cancers in 185 Countries. CA A Cancer J. Clin. 2021, 71, 209-249. [CrossRef]

2. Siegel, R.L.; Miller, K.D.; Fuchs, H.E.; Jemal, A. Cancer Statistics, 2021. CA A Cancer J. Clin. 2021, 71, 7-33. [CrossRef]

3. Zahreddine, H.K. Borden Mechanisms and Insights into Drug Resistance in Cancer. Front. Pharmacol. 2013, 4, 28. [CrossRef]

4. Luqmani, Y.A. Mechanisms of Drug Resistance in Cancer Chemotherapy. Med. Princ. Pract. 2005, 14 (Suppl. 1), 35-48. [CrossRef]

5. Pritchard, J.R.; Lauffenburger, D.A.; Hemann, M.T. Hemann Understanding Resistance to Combination Chemotherapy. Drug Resist. Updates Rev. Comment. Antimicrob. Anticancer. Chemother. 2012, 15, 249-257.

6. Wang, H.; Huang, Y. Combination Therapy Based on Nano Codelivery for Overcoming Cancer Drug Resistance. Med. Drug Discov. 2020, 6, 100024. [CrossRef]

7. Poulose, A.C.; Veeranarayanan, S.; Mohamed, M.S.; Aburto, R.R.; Mitcham, T.; Bouchard, R.; Ajayan, P.M.; Sakamoto, Y.; Maekawa, T.; Kumar, D.S. Multifunctional $\mathrm{Cu}_{2}-\mathrm{xTe}$ Nanocubes Mediated Combination Therapy for Multi-Drug Resistant MDA MB 453. Sci. Rep. 2016, 6, 35961. [CrossRef]

8. Li, Z.; Chen, Y.; Yang, Y.; Yu, Y.; Zhang, Y.; Zhu, D.; Yu, X.; Ouyang, X.; Xie, Z.; Zhao, Y.; et al. Recent Advances in NanomaterialsBased Chemo-Photothermal Combination Therapy for Improving Cancer Treatment. Front. Bioeng. Biotechnol. $2019,7,293$. [CrossRef]

9. $\quad$ Fang, T.; Zhang, J.; Zuo, T.; Wu, G.; Xu, Y.; Yang, Y.; Yang, J.; Shen, Q. Chemo-Photothermal Combination Cancer Therapy with ROS Scavenging, Extracellular Matrix Depletion, and Tumor Immune Activation by Telmisartan and Diselenide-Paclitaxel Prodrug Loaded Nanoparticles. ACS Appl. Mater. Interfaces 2020, 12, 31292-31308. [CrossRef]

10. Du, X.-F.; Li, Y.; Long, J.; Zhang, W.; Wang, D.; Li, C.-R.; Zhao, M.-X.; Lai, Y. Fabrication of Cisplatin-Loaded Polydopamine Nanoparticles via Supramolecular Self-Assembly for Photoacoustic Imaging Guided Chemo-Photothermal Cancer Therapy. Appl. Mater. Today 2021, 23, 101019. [CrossRef]

11. Abbasian, M.; Mahmoodzadeh, F.; Salehi, R.; Amirshaghaghi, A. Chemo-Photothermal Therapy of Cancer Cells Using Gold Nanorod-Cored Stimuli-Responsive Triblock Copolymer. New J. Chem. 2017, 41, 12777-12788. [CrossRef]

12. Zhu, H.; Sarkar, S.; Scott, L.; Danelisen, I.; Trush, M.A.; Jia, Z.; Li, Y.R. Doxorubicin Redox Biology: Redox Cycling, Topoisomerase Inhibition, and Oxidative Stress. React. Oxyg. Species 2016, 1, 189-198. [CrossRef]

13. Fan, C.; Zheng, W.; Fu, X.; Li, X.; Wong, Y.-S.; Chen, T. Strategy to Enhance the Therapeutic Effect of Doxorubicin in Human Hepatocellular Carcinoma by Selenocystine, a Synergistic Agent that Regulates the ROS-Mediated Signaling. Oncotarget 2014, 5, 2853-2863. [CrossRef]

14. Ijäs, H.; Shen, B.; Heuer-Jungemann, A.; Keller, A.; Kostiainen, M.A.; Liedl, T.; Ihalainen, J.; Linko, V. Unraveling the Interaction between Doxorubicin and DNA Origami Nanostructures for Customizable Chemotherapeutic Drug Release. Nucleic Acids Res. 2021, 49, 3048-3062. [CrossRef]

15. Qiao, X.; van der Zanden, S.Y.; Wander, D.P.A.; Borràs, D.M.; Song, J.-Y.; Li, X.; van Duikeren, S.; van Gils, N.; Rutten, A.; van Herwaarden, T.; et al. Uncoupling DNA Damage from Chromatin Damage to Detoxify Doxorubicin. Proc. Natl. Acad. Sci. USA 2020, 117, 15182. [CrossRef]

16. Wang, N.; Liu, C.; Yao, W.; Zhou, H.; Yu, S.; Chen, H.; Qiao, W. Endogenous Reactive Oxygen Species Burst Induced and Spatiotemporally Controlled Multiple Drug Release by Traceable Nanoparticles for Enhancing Antitumor Efficacy. Biomater. Sci. 2021, 9, 4968-4983. [CrossRef] 
17. Kim, D.; Park, S.; Yoo, H.; Park, S.; Kim, J.; Yum, K.; Kim, K.; Kim, H. Overcoming Anticancer Resistance by Photodynamic Therapy-Related Efflux Pump Deactivation and Ultrasound-Mediated Improved Drug Delivery Efficiency. Nano Converg. 2020, 7, 30. [CrossRef]

18. Ghosn, Y.; Kamareddine, M.H.; Tawk, A.; Elia, C.; El Mahmoud, A.; Terro, K.; El Harake, N.; El-Baba, B.; Makdessi, J.; Farhat, S. Inorganic Nanoparticles as Drug Delivery Systems and Their Potential Role in the Treatment of Chronic Myelogenous Leukaemia. Technol. Cancer Res. Treat. 2019, 18, 1533033819853241. [CrossRef]

19. Shi, Z.; Zhou, Y.; Fan, T.; Lin, Y.; Zhang, H.; Mei, L. Inorganic Nano-Carriers Based Smart Drug Delivery Systems for Tumor Therapy. Smart Mater. Med. 2020, 1, 32-47. [CrossRef]

20. Wang, F.; Li, C.; Cheng, J.; Yuan, Z. Recent Advances on Inorganic Nanoparticle-Based Cancer Therapeutic Agents. Int. J. Environ. Res. Public Health 2016, 13, 1182. [CrossRef]

21. Kuthati, Y.; Busa, P.; Tummala, S.; Rao, V.; Davuluri, V.; Ho, Y.-P.; Wong, C.-S. Mesoporous Polydopamine Nanoparticles Attenuate Morphine Tolerance in Neuropathic Pain Rats by Inhibition of Oxidative Stress and Restoration of the Endogenous Antioxidant System. Antioxidants 2021, 10, 195. [CrossRef]

22. Wang, Y.; Zhao, Q.; Han, N.; Bai, L.; Li, J.; Che, E.; Hu, L.; Zhang, Q.; Jiang, T.; Wang, S. Mesoporous Silica Nanoparticles in Drug Delivery and Biomedical Applications. Nanomed. Nanotechnol. Biol. Med. 2015, 11, 313-327. [CrossRef]

23. Niculescu, V.-C. Mesoporous Silica Nanoparticles for Bio-Applications. Front. Mater. 2020, 7, 36. [CrossRef]

24. Xu, C.; Lei, C.; Yu, C. Mesoporous Silica Nanoparticles for Protein Protection and Delivery. Front. Chem. 2019, 7, 290. [CrossRef]

25. Kuthati, Y.; Kankala, R.K.; Busa, P.; Lin, S.-X.; Deng, J.-P.; Mou, C.-Y.; Lee, C.-H. Phototherapeutic Spectrum Expansion through Synergistic Effect of Mesoporous Silica Trio-Nanohybrids against Antibiotic-Resistant Gram-Negative Bacterium. J. Photochem. Photobiol. B Biol. 2017, 169, 124-133. [CrossRef]

26. Castillo, R.R.; Lozano, D.; Vallet-Regí, M. Mesoporous Silica Nanoparticles as Carriers for Therapeutic Biomolecules. Pharmaceutics 2020, 12, 432. [CrossRef]

27. Zhou, Y.; Quan, G.; Wu, Q.; Zhang, X.; Niu, B.; Wu, B.; Huang, Y.; Pan, X.; Wu, C. Mesoporous Silica Nanoparticles for Drug and Gene Delivery. Acta Pharm. Sinica. B 2018, 8, 165-177. [CrossRef]

28. Lin, C.-H.; Kankala, R.K.; Busa, P.; Lee, C.-H. Hydrophobicity-Tuned Periodic Mesoporous Organo-Silica Nanoparticles for Photodynamic Therapy. Int. J. Mol. Sci. 2020, 21, 2586. [CrossRef]

29. Li, Z.; Zhang, Y.; Feng, N. Mesoporous Silica Nanoparticles: Synthesis, Classification, Drug Loading, Pharmacokinetics, Biocompatibility, and Application in Drug Delivery. Expert Opin. Drug Deliv. 2019, 16, 219-237. [CrossRef]

30. Trzeciak, K.; Chotera-Ouda, A.; Bak-Sypien, I.; Potrzebowski, M. Mesoporous Mesoporous Silica Particles as Drug Delivery Systems-The State of the Art in Loading Methods and the Recent Progress in Analytical Techniques for Monitoring These Processes. Pharmaceutics 2021, 13, 950. [CrossRef]

31. Bhattacharyya, S.; Wang, H.; Ducheyne, P. Polymer-Coated Mesoporous Silica Nanoparticles for the Controlled Release of Macromolecules. Acta Biomater. 2012, 8, 3429-3435. [CrossRef]

32. Bansal, K.K.; Mishra, D.K.; Rosling, A.; Rosenholm, J.M. Therapeutic Potential of Polymer-Coated Mesoporous Silica Nanoparticles. Appl. Sci. 2020, 10, 289. [CrossRef]

33. Xing, L.; Zheng, H.; Cao, Y.; Che, S. Coordination Polymer Coated Mesoporous Silica Nanoparticles for pH-Responsive Drug Release. Adv. Mater. 2012, 24, 6433-6437. [CrossRef]

34. Song, Z.; Shi, J.; Zhang, Z.; Qi, Z.; Han, S.; Cao, S. Mesoporous Silica-Coated Gold Nanorods with a Thermally Responsive Polymeric Cap for Near-Infrared-Activated Drug Delivery. J. Mater. Sci. 2018, 53, 7165-7179. [CrossRef]

35. Choi, S.R.; Jang, D.J.; Kim, S.; An, S.; Lee, J.; Oh, E.; Kim, J. Polymer-Coated Spherical Mesoporous Silica for pH-Controlled Delivery of Insulin. J. Mater. Chem. B 2014, 2, 616-619. [CrossRef]

36. Yang, Y.; Yan, X.; Cui, Y.; He, Q.; Li, D.; Wang, A.; Fei, J.; Li, J. Preparation of Polymer-Coated Mesoporous Silica Nanoparticles Used for Cellular Imaging by a "Graft-from" Method. J. Mater. Chem. 2008, 18, 5731-5737. [CrossRef]

37. Tang, H.; Zhao, W.; Yu, J.; Li, Y.; Zhao, C. Recent Development of pH-Responsive Polymers for Cancer Nanomedicine. Molecules 2019, 24, 4. [CrossRef]

38. Alsehli, M. Polymeric Nanocarriers as Stimuli-Responsive Systems for Targeted Tumor (Cancer) Therapy: Recent Advances in Drug Delivery. Saudi Pharm. J. 2020, 28, 255-265. [CrossRef]

39. Wang, X.; Li, X.; Ito, A.; Sogo, Y.; Watanabe, Y.; Tsuji, N.M.; Ohno, T. Biodegradable Metal Ion-Doped Mesoporous Silica Nanospheres Stimulate Anticancer Th1 Immune Response in Vivo. ACS Appl. Mater. Interfaces 2017, 9, 43538-43544. [CrossRef]

40. Tahmasbi, L.; Sedaghat, T.; Motamedi, H.; Kooti, M. Mesoporous Silica Nanoparticles Supported Copper(II) and Nickel(II) Schiff Base Complexes: Synthesis, Characterization, Antibacterial Activity and Enzyme Immobilization. J. Solid State Chem. 2018, 258, 517-525. [CrossRef]

41. Pan, Y.; Zhou, S.; Li, Y.; Parshad, B.; Li, W.; Haag, R. Novel Dendritic Polyglycerol-Conjugated, Mesoporous Silica-Based Targeting Nanocarriers for Co-Delivery of Doxorubicin and Tariquidar to Overcome Multidrug Resistance in Breast Cancer stem Cells. J. Control. Release 2021, 330, 1106-1117. [CrossRef]

42. Abdullah, C.S.; Ray, P.; Alam, S.; Kale, N.; Aishwarya, R.; Morshed, M.; Dutta, D.; Hudziak, C.; Banerjee, S.K.; Mallik, S.; et al Chemical Architecture of Block Copolymers Differentially Abrogate Cardiotoxicity and Maintain the Anticancer Efficacy of Doxorubicin. Mol. Pharm. 2020, 17, 4676-4690. [CrossRef] 
43. Shi, M.; Zhang, J.; Li, J.; Fan, Y.; Wang, J.; Sun, W.; Yang, H.; Peng, C.; Shen, M.; Shi, X. Polydopamine-Coated Magnetic Mesoporous Silica Nanoparticles for Multimodal Cancer Theranostics. J. Mater. Chem. B 2019, 7, 368-372. [CrossRef]

44. Zhang, X.; Achazi, K.; Steinhilber, D.; Kratz, F.; Dernedde, J.; Haag, R. A Facile Approach for Dual-Responsive Prodrug Nanogels Based on Dendritic Polyglycerols with Minimal Leaching. J. Control. Release 2014, 174, 209-216. [CrossRef]

45. Pada, A.-K.; Desai, D.; Sun, K.; Govardhanam, N.P.; Törnquist, K.; Zhang, J.; Rosenholm, J.M. Comparison of PolydopamineCoated Mesoporous Silica Nanorods and Spheres for the Delivery of Hydrophilic and Hydrophobic Anticancer Drugs. Int. J. Mol. Sci. 2019, 20, 3408. [CrossRef]

46. Zhu, M.; Shi, Y.; Shan, Y.; Guo, J.; Song, X.; Wu, Y.; Wu, M.; Lu, Y.; Chen, W.; Xu, X.; et al. Recent Developments in Mesoporous Polydopamine-Derived Nanoplatforms for Cancer Theranostics. J. Nanobiotechnology 2021, 19, 387. [CrossRef]

47. Li, X.; Xie, C.; Xia, H.; Wang, Z. pH and Ultrasound Dual-Responsive Polydopamine-Coated Mesoporous Silica Nanoparticles for Controlled Drug Delivery. Langmuir 2018, 34, 9974-9981. [CrossRef]

48. Lei, W.; Sun, C.; Jiang, T.; Gao, Y.; Yang, Y.; Zhao, Q.; Wang, S. Polydopamine-Coated Mesoporous Silica Nanoparticles for Multi-Responsive Drug Delivery and Combined Chemo-Photothermal Therapy. Mater. Sci. Eng. C. 2019, 105, 110103. [CrossRef]

49. Huang, C.; Zhang, L.; Guo, Q.; Zuo, Y.; Wang, N.; Wang, H.; Kong, D.; Zhu, D.; Zhang, L. Robust Nanovaccine Based on Polydopamine-Coated Mesoporous Silica Nanoparticles for Effective Photothermal-Immunotherapy Against Melanoma. Adv. Funct. Mater. 2021, 31, 2010637. [CrossRef]

50. Liao, J.; Zhang, H.; Wang, X. Polydopamine-Doped Virus-like Mesoporous Silica Coated Reduced Graphene Oxide Nanosheets for Chemo-Photothermal Synergetic Therapy. J. Biomater. Appl. 2020, 35, 28-38. [CrossRef]

51. Tran, H.Q.; Bhave, M.; Xu, G.; Sun, C.; Yu, A. Synthesis of Polydopamine Hollow Capsules via a Polydopamine Mediated Silica Water Dissolution Process and Its Application for Enzyme Encapsulation. Front. Chem. 2019, 7, 468. [CrossRef]

52. Duo, Y.; Li, Y.; Chen, C.; Liu, B.; Wang, X.; Zeng, X.; Chen, H. DOX-Loaded pH-Sensitive Mesoporous Silica Nanoparticles Coated with PDA and PEG Induce Pro-Death Autophagy in Breast Cancer. RSC Adv. 2017, 7, 39641-39650. [CrossRef]

53. Wei, Y.; Gao, L.; Wang, L.; Shi, L.; Wei, E.; Zhou, B.; Zhou, L.; Ge, B. Polydopamine and Peptide Decorated Doxorubicin-Loaded Mesoporous Silica Nanoparticles as a Targeted Drug Delivery System for Bladder Cancer Therapy. Drug Deliv. 2017, $24,681-691$. [CrossRef]

54. Day, C.; Sweetman, M.; Song, Y.; Plush, S.; Garg, S. Functionalized Mesoporous Silica Nanoparticles as Delivery Systems for Doxorubicin: Drug Loading and Release. Appl. Sci. 2021, 11, 6121. [CrossRef]

55. Tao, C.; Chen, T.; Liu, H.; Su, S. Preparation and Adsorption Performance Research of Large-Volume Hollow Mesoporous Polydopamine Microcapsules. MRS Commun. 2019, 9, 744-749. [CrossRef]

56. Cheng, W.; Liang, C.; Xu, L.; Liu, G.; Gao, N.; Tao, W.; Luo, L.; Zuo, Y.; Wang, X.; Zhang, X.; et al. TPGS-Functionalized Polydopamine-Modified Mesoporous Silica as Drug Nanocarriers for Enhanced Lung Cancer Chemotherapy against Multidrug Resistance. Small 2017, 13, 1700623. [CrossRef]

57. Busa, P.; Koutavarapu, R.; Lee, D.-Y.; Shim, J.; Kuthati, Y. Hierarchical Two-Dimensional Layered Double Hydroxide Coated Polydopamine Nanocarriers for Combined Chemodynamic and Photothermal Tumor Therapy. Coatings 2021, 11, 1008. [CrossRef]

58. Lin, C.-W.; Lin, S.-X.; Kankala, R.K.; Busa, P.; Deng, J.-P.; Lue, S.-I.; Liu, C.-L.; Weng, C.-F.; Lee, C.-H. Surface-Functionalized Layered Double Hydroxide Nanocontainers as Bile Acid Sequestrants for Lowering Hyperlipidemia. Int. J. Pharm. 2020, 590, 119921. [CrossRef]

59. Jin, R.; Liu, Z.; Bai, Y.; Zhou, Y.; Chen, X. Multiple-Responsive Mesoporous Silica Nanoparticles for Highly Accurate Drugs Delivery to Tumor Cells. ACS Omega 2018, 3, 4306-4315. [CrossRef]

60. Kuthati, Y.; Busa, P.; Davuluri, V.N.G.; Wong, C.S. Manganese Oxide Nanozymes Ameliorate Mechanical Allodynia in a Rat Model of Partial Sciatic Nerve-Transection Induced Neuropathic Pain. Int. J. Nanomed. 2019, 14, 10105-10117. [CrossRef]

61. Dong, K.; Zhao, Z.-Z.; Kang, J.; Lin, L.-R.; Chen, W.-T.; Liu, J.-X.; Wu, X.-L.; Lu, T.-L. Cinnamaldehyde and Doxorubicin Co-Loaded Graphene Oxide Wrapped Mesoporous Silica Nanoparticles for Enhanced MCF-7 Cell Apoptosis. Int. J. Nanomed. 2020, 15, 10285-10304. [CrossRef]

62. Xing, Y.; Zhang, J.; Chen, F.; Liu, J.; Cai, K. Mesoporous Polydopamine Nanoparticles with Co-Delivery Function for Overcoming Multidrug Resistance via Synergistic Chemo-Photothermal Therapy. Nanoscale 2017, 9, 8781-8790. [CrossRef]

63. Li, X.-J.; Li, W.-T.; Li, Z.-H.-R.; Zhang, L.-P.; Gai, C.-C.; Zhang, W.-F.; Ding, D.-J. Iron-Chelated Polydopamine Decorated Doxorubicin-Loaded Nanodevices for Reactive Oxygen Species Enhanced Cancer Combination Therapy. Front. Pharmacol. 2019, 10, 75. [CrossRef]

64. Liu, D.; Mori, A.; Huang, L. Role of Liposome Size and RES Blockade in Controlling Biodistribution and Tumor Uptake of GM1-Containing Liposomes. Biochim. Biophys Acta 1992, 1104, 95-101. [CrossRef]

65. Shen, J.; He, Q.; Gao, Y.; Shi, J.; Li, Y. Mesoporous Silica Nanoparticles Loading Doxorubicin Reverse Multidrug Resistance: Performance and Mechanism. Nanoscale 2011, 3, 4314-4322. [CrossRef]

66. Yuan, Z.; Pan, Y.; Cheng, R.; Sheng, L.; Wu, W.; Pan, G.; Feng, Q.; Cui, W. Doxorubicin-Loaded Mesoporous Silica Nanoparticle Composite Nanofibers for Long-Term Adjustments of Tumor Apoptosis. Nanotechnology 2016, 27, 245101. [CrossRef]

67. Jain, S.; Khan, T.A.; Patil, Y.P.; Pagariya, D.; Kishore, N.; Tapryal, S.; Naik, A.D.; Naik, S.G. Bio-Affinity of Copper(II) Complexes with Nitrogen and Oxygen Donor Ligands: Synthesis, Structural Studies and in Vitro DNA and HSA Interaction of Copper(II) Complexes. J. Photochem. Photobiol. B Biol. 2017, 174, 35-43. [CrossRef] 
68. Zeng, X.; Liu, G.; Tao, W.; Ma, Y.; Zhang, X.; He, F.; Pan, J.; Mei, L.; Pan, G. A Drug-Self-Gated Mesoporous Antitumor Nanoplatform Based on pH-Sensitive Dynamic Covalent Bond. Adv. Funct. Mater. 2017, 27, 1605985. [CrossRef]

69. Rahoui, N.; Jiang, B.; Hegazy, M.; Taloub, N.; Wang, Y.; Yu, M.; Huang, Y.D. Gold Modified Polydopamine Coated Mesoporous Silica Nano-Structures for Synergetic Chemo-Photothermal Effect. Colloids Surf. B Biointerfaces 2018, 171, 176-185. [CrossRef]

70. Chen, X.; Cheng, X.; Soeriyadi, A.H.; Sagnella, S.M.; Lu, X.; Scott, J.A.; Lowe, S.B.; Kavallaris, M.; Gooding, J.J. Stimuli-Responsive Functionalized Mesoporous Silica Nanoparticles for Drug Release in Response to Various Biological Stimuli. Biomater. Sci. 2014, 2, 121-130. [CrossRef]

71. Chang, D.; Gao, Y.; Wang, L.; Liu, G.; Chen, Y.; Wang, T.; Tao, W.; Mei, L.; Huang, L.; Zeng, X. Polydopamine-Based Surface Modification of Mesoporous Silica Nanoparticles as $\mathrm{pH}$-Sensitive Drug Delivery Vehicles for Cancer Therapy. J. Colloid Interface Sci. 2015, 463, 279-287. [CrossRef]

72. Tiwari, A.P.; Bhattarai, D.P.; Maharjan, B.; Ko, S.W.; Kim, H.Y.; Park, C.H.; Kim, C.S. Polydopamine-Based Implantable Multifunctional Nanocarpet for Highly Efficient Photothermal-Chemo Therapy. Sci. Rep. 2019, 9, 2943. [CrossRef]

73. Jia, C.; Wu, H.; Luo, K.; Hao, W.; Wang, S.; Huang, M. Magnetic Silica Nanosystems With NIR-Responsive and Redox Reaction Capacity for Drug Delivery and Tumor Therapy. Front. Chem. 2020, 8, 567652. [CrossRef]

74. Ruan, L.; Wang, M.; Zhou, M.; Lu, H.; Zhang, J.; Gao, J.; Chen, J.; Hu, Y. Doxorubicin-Metal Coordinated Micellar Nanoparticles for Intracellular Codelivery and Chemo/Chemodynamic Therapy in Vitro. ACS Appl. Bio Mater. 2019, 2, 4703-4707. [CrossRef]

75. Yao, L.; Tang, Y.; Cao, W.; Cui, Y.; Qian, G. Highly Efficient Encapsulation of Doxorubicin Hydrochloride in Metal-Organic Frameworks for Synergistic Chemotherapy and Chemodynamic Therapy. ACS Biomater. Sci. Eng. 2021, 7, 4999-5006. [CrossRef]

76. Xue, T.; Xu, C.; Wang, Y.; Wang, Y.; Tian, H.; Zhang, Y. Doxorubicin-Loaded Nanoscale Metal-Organic Framework for TumorTargeting Combined Chemotherapy and Chemodynamic Therapy. Biomater. Sci. 2019, 7, 4615-4623. [CrossRef]

77. Chen, C.; Tang, W.; Jiang, D.; Yang, G.; Wang, X.; Zhou, L.; Zhang, W.; Wang, P. Hyaluronic Acid Conjugated Polydopamine Functionalized Mesoporous Silica Nanoparticles for Synergistic Targeted Chemo-Photothermal Therapy. Nanoscale 2019, 11, 11012-11024. [CrossRef]

78. Shao, L.; Zhang, R.; Lu, J.; Zhao, C.; Deng, X.; Wu, Y. Mesoporous Silica Coated Polydopamine Functionalized Reduced Graphene Oxide for Synergistic Targeted Chemo-Photothermal Therapy. ACS Appl. Mater. Interfaces 2017, 9, 1226-1236. [CrossRef]

79. Zhang, Y.; Eltayeb, O.; Meng, Y.; Zhang, G.; Shuang, S.; Dong, C. Tumor Microenvironment Responsive Mesoporous Silica Nanoparticles for Dual Delivery of Doxorubicin and Chemodynamic Therapy (CDT) agent. New J. Chem. 2020, 44, $2578-2586$. [CrossRef]

80. Xin, J.; Deng, C.; Aras, O.; Zhou, M.; Wu, C.; An, F. Chemodynamic Nanomaterials for Cancer Theranostics. J. Nanobiotechnology 2021, 19, 192. [CrossRef]

81. Poinard, B.; Neo, S.Z.Y.; Yeo, E.L.L.; Heng, H.P.S.; Neoh, K.G.; Kah, J.C.Y. Polydopamine Nanoparticles Enhance Drug Release for Combined Photodynamic and Photothermal Therapy. ACS Appl. Mater. Interfaces 2018, 10, 21125-21136. [CrossRef] 